\title{
Utilization of Satellite-Satellite Tracking Data for Determination of the Geocentric Gravitational Constant (GM)
}

C. F. Martin

and

I. H. Oh 
. 
NASA Contractor Report 156856

\title{
Utilization of Satellite-Satellite Tracking Data for Determination of the Geocentric Gravitational Constant (GM)
}

\author{
C. F. Martin and I. H. Oh
}

EG\&G Washington Analytical Services Center, Inc.

Riverdale, Maryland 20840

Prepared Under Contract No. NAS6-2495

\section{N/SA}

National Aeronautics and

Space Administration

Wallops Flight Center

Wallops Island, Virginia 23337

AC 804 824-3411 


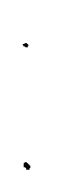


Page

1.0 INTRODUCTION

2.0 METHOD AND DATA SET

3.0

TRACKING POINT CORRECTIONS

4.0

ESTIMATED VALUES OF GM

5.0

STATION POSITIONS

6.0

CONCLUSIONS

20 
Page

Figure 1. Published Values of GM with Standard Deviations Less than $0.8 \mathrm{~km}^{3} / \mathrm{sec}^{2}$

Figure 2. Ground tracks for Single Pass Laser Arcs 9

Figure 3. Effect of Tracking Point Correction on SSE Measurements on GEOS-3 REV 240

Figure 4. GEOS-3 Orbit Differences Due to Tracking Point Corrections (Orbit Without Correction Orbit With Correction)

Figure 5. SSE Range Rate RSS for Different Gravity Models in 4 Half Day Arcs 
Table 1. Summary of SSE Range Rate and Ground Tracking Data (Half-Day Arcs)

Table 2. Summary of SSE Range Rate and Ground Tracking Data (Short Arcs with Two Consecutive SSE Passes)

Table 3. Summary of Two Pass Arcs of Laser Data

Table 4. Effect on GM Due to SSE Tracking Point Correction

Táble 5. Recovered Values of GM (in $\mathrm{km}^{3} / \mathrm{sec}^{2}$ ) from ATS- 6 to GEOS-3 SSE Range Rate

Data and Ground Tracking of GEOS-3

Table 6. Estimated Station Positions Using GEM 10 and 4 Half Day Arcs of SSE Data

Table 7. Estimated Baselines and Station Heights Using Different Gravity Models 


\section{T.0 INTRODUCTION}

Prior to 1975, most determinations of the geocentric gravitational constant (GM) employed radiometric data from near-earth tracking of lunar and interplanetary probes. Reported GM results having sigmas less than $0.8 \mathrm{~km}^{3} / \mathrm{sec}^{2}$ are shown in Figure 1. GM values from Rangers 8 and 9 (Sjogren, et.al., 1966), Surveyors 5 and 6 (Wong, 1968), Pioneer 7 (Anderson and Hilt, 1969), and Mariner 5 (Pease, et.al., 1969) are all consistent at the 1o level. A value of $398601.13 \mathrm{~km}^{3} / \mathrm{sec}^{2}$, based on Ranger results, was adopted by the Smithsonian Astrophysical Observatory for both their 1966 Standard Earth (Lundquist and Veis, 1966) and 1969 Standard Earth (Gaposchkin and Lambeck, 1970), and was widely used prior to Mariner 9 for earth satellite orbit determinations. The Lunar Orbiter 2 GM value (Mottinger and Sjogren, 1967) seems to have been largely ignored, probably because of $i$ ts inconsistency with the lunar probe results and the reference of the investigators for a "more realistic" sigma of $0.7 \mathrm{~km}^{3} / \mathrm{sec}^{2}$ (Esposito and Wong, 1972). The Venera GIl (Akim, et.al., 1971) also had virtually no impact at the time of its publication, due to its inconsistency with the accepted value and the listing of its error at $1.0 \mathrm{~km}^{3} / \mathrm{sec}^{2}$ maximum possible error. As shown in Figure 1, however, the Lunar Orbiter 2 and Venera results are consistent with more recent GM determinations.

Discounting the Lunar Orbiter and Venera results, the Mariner 9 GM, first presented in 1972 (Esposito and Wong, 1972), was a sharp drop from previous values. Refined analysis of the Mariner 9 data and preliminary Mariner 10 analysis (Esposito and $\mathrm{Ng}, 1976$ ) produced even further reductions in GM estimates. The most recent GM estimates based on interplanetary probe tracking are from Vikings 1 and 2 (Esposito, 1978) and bracket the Mariner 9 and 10 values.

Within the last three years, several new methods have been used for GM determination, with results (shown in Figure 1) that are consistent with those from Mariner 9 and later radiometric tracking of interplanetary probes. These methods include lunar laser ranging (Williams, 1977), lunar laser ranging combined with very long baseline interferometry (VLBI) observations of lunar radio transmitters (King, et.al., 1976), laser ranging of the LAGEOS 


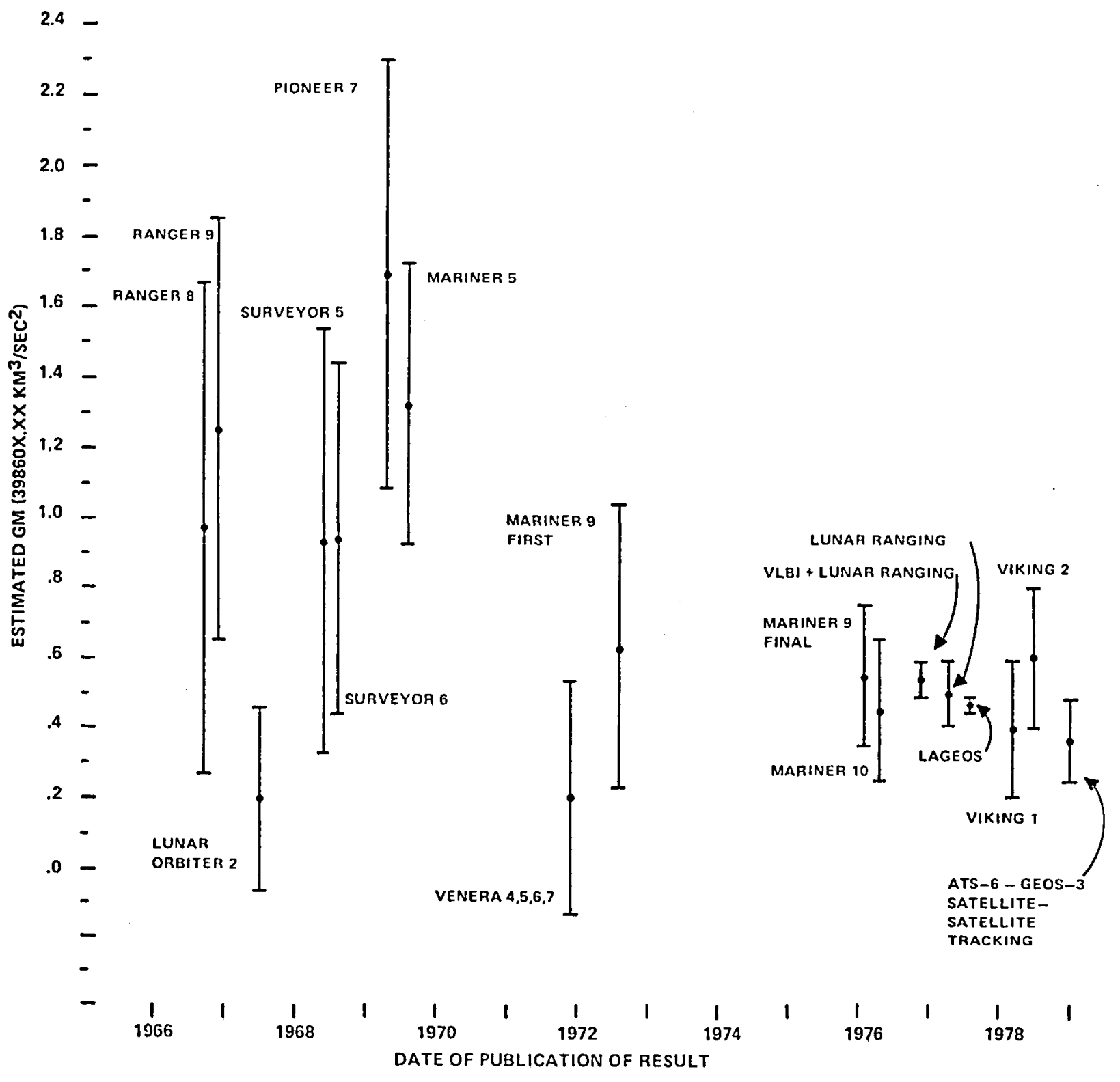

FIGURE 1. PUBLISHED VALUES OF GM WITH STANDARD DEVIATIONS LESS THAN $0.8 \mathrm{~km}^{3} / \mathrm{sec}^{2}$. BARS SHOW T/I ERROR ESTIMATES. FOR VENERA 4,5,6,7 THE PUBLISHED $1.0 \mathrm{~km} 3 / \mathrm{scc}^{2}$ "MAXIMUM POSSIBLE ERROR" (AKIM, ET. AL., 1971) WAS ASSUMED TO BE A $3 u$ VALUE. ALL VALUES HAVE BEEN REFERENCED TO A SPEED OF LIGHT OF $299792.458 \mathrm{~km} / \mathrm{sec}$. 
satellite (Lerch, et.al., 1977), and the satellite-satellite tracking method to be discussed in this paper. Each of these methods has produced results with sigmas which are lower than any of the results from interplanetary probe tracking. Whether this is indicative of a higher level of accuracy, or less conservatism among investigators, remains to be seen from more refined data analyses and new Gil determinations. However, the post 1975 results are consistent to within the quoted lo levels, suggesting that very accurate results are now being obtained, particularly from methods using laser ranging data. On the other hand, it should be emphasized that accurate results will be consistent, but that consistent results are not necessarily accurate. The effects of measurement noise on a GM determination are easy to calculate, but the effects of systematic errors can be very difficult to reliably assess due to problems either in modeling the errors or in estimating their magnitude. Furthermore, the same systematic errors can affect different GM determination methods in a similar manner. The primary advantage of using different methods is that the common systematic errors are minimized, thus providing checks on the results and error analyses for the different solutions. It is believed that the method discussed in this paper has some error sources that are common to the LAGEOS solution*, but is unlikely to have any significant errors common to any of the other solutions.

\subsection{METHOD AND DATA SET}

Accurate determination of GM using only low altitude earth orbiting satellites has not been possible due to uncertainties in the geopotential (e.g., as expressed via spherical harmonics) and high correlations between simultaneously estimated GM and station position heights. The use of both a high altitude satellite and a low altitude satellite, along with the constraint obtained from measuring the relative motion between the satellites leads to reduced sensitivity to geopotential model errors, and a reduction in the correlations between estimated station heights and GM.

\footnotetext{
* Primarily the geopotential coefficient set.
} 
During the first two months after the launch of GEOS-3 in Apri1, 1975, Satellite-Satellite Tracking Experiment (SSE) Rosman (N.C.) to ATS-6 to GEOS-3 range rate data was taken. GEOS-3 is in a near circular orbit with a nominal altitude of $843 \mathrm{~km}$, and an inclination of $115^{\circ}$. ATS-6 is in a geosyncronous orbit and, during the period of interest, was located at longitude $94^{\circ} \mathrm{W}$. In addition to the SSE range rate data, ground tracking of GEOS-3 by lasers and $C$-band radars was also used. Although some ranging data from Rosman to ATS- 6 to GEOS- 3 was taken, none was used because of bias uncertainties.

From error analyses of Gll estimation using SSE data, the dominant error sources were identified as station positions, geopotential coefficients, and solar radiation pressure on ATS-6. The effects of these error sources were minimized by using arc lengths of one half day or less, and the best available geopotential model. Since no sufficiently accurate station position set was available, the coordinates of all the GEOS-3 tracking stations were adjusted, except for one longitude which was arbitrarily fixed.

Four sets of data were selected for use in various combinations. Table 1 shows the basic set of half-day arcs, each containing 4 passes of SSE data along with at least 4 passes of ground tracking by the GEOS-3 calibration area stations indicated. Two of these arcs begin with North-South passes through the calibration area and two begin with South-North passes.

The second set of data, shown in Table 2 , contains 1-2 revolution arcs of GEOS-3, each including SSE tracks on successive revolutions. Again there is a geometric balance of passes between North-South and South-North passes in order to obtain the maximum degree of cancellation of geopotential model errors.

The third set of data (Table 3) contains only NASA laser tracking of GEOS-3, with the arc lengths only slightly greater than one revolution. This data set was chosen because of $i$ ts high concentration of high accuracy unbiased ranging data from the three INASA laser sites at Goddard, Bermuda and Grand Turk. (Only Goddard and Grand Turk lasers tracked during the SSE tracking period.) Although this laser data set did not contribute strength directly to the GM recovery, it did provide strength for station position estimation. 
TABLE 1. SUMMARY OF SSE RANGE RATE AND GROUND TRACKING DATA

(HALF-DAY ARCS)

\begin{tabular}{|c|c|c|c|c|}
\hline & DATA SPAN & $\begin{array}{l}\text { REV. NO. } \\
\text { OF GEOS-3 } \\
\text { ORBIT } \\
\end{array}$ & STATIONS TRACKING* & DIRECTION \\
\hline \multirow[t]{2}{*}{$\begin{array}{l}\text { /26/75 } \\
\text { ARLF DAY }\end{array}$} & $21^{\mathrm{h}} 15^{\mathrm{m}}-09^{\mathrm{h}} 50^{\mathrm{m}}, 4 / 27$ & $\begin{array}{l}239 \\
240 \\
241\end{array}$ & $\begin{array}{l}\text { SSE } \\
\text { SSE, } 4760,4860,7063 \\
\quad 4860\end{array}$ & $N-S$ \\
\hline & & $\begin{array}{l}245 \\
246\end{array}$ & $\begin{array}{l}\text { SSE, } 4760,4840,7063 \\
\text { SSE, 4760, 4840, } 7068,7063\end{array}$ & $S-N$ \\
\hline \multirow{2}{*}{$\begin{array}{l}\text { H/27/75 } \\
\text { HALF DAY } \\
\text { ARC }\end{array}$} & $06^{h_{4}} 44_{-00^{\mathrm{h}}} 37^{\dot{m}}, 4 / 28$ & $\begin{array}{l}245 \\
246\end{array}$ & $\begin{array}{l}\text { SSE, } 4760,4840,7063 \\
\text { SSE, 4760, 4840, } 7068,7063\end{array}$ & $S-N$ \\
\hline & - & $\begin{array}{l}253 \\
254 \\
255\end{array}$ & $\begin{array}{l}\text { SSE, } 4760 \\
\text { SSE, } 4760,4840,7068 \\
\quad 4840\end{array}$ & $\mathrm{~N}-\mathrm{S}$ \\
\hline \multirow[t]{2}{*}{$\begin{array}{l}\text { T/10/75 } \\
\text { HALF DAY }\end{array}$} & $22^{h} 50^{m}-10^{h} 30^{m}, 5 / 11$ & $\begin{array}{l}438 \\
439\end{array}$ & $\begin{array}{l}\text { SSE, } 4760 \\
\text { SSE, } 4760,4860\end{array}$ & $\mathrm{~N}-\mathrm{S}$ \\
\hline & & $\begin{array}{l}444 \\
445\end{array}$ & $\begin{array}{l}\text { SSE, } 4760,4840 \\
\text { SSE, } 4840,7063\end{array}$ & $S-N$ \\
\hline \multirow[t]{2}{*}{$\begin{array}{l}\text { HALF DAY } \\
\text { ARC }\end{array}$} & $08^{h_{10} m_{-01} h_{57} m, 5 / 13}$ & $\begin{array}{l}458 \\
459\end{array}$ & $\begin{array}{l}\text { SSE, } 4760,4860 \\
\text { SSE, } 4760,4860,7063\end{array}$ & $S-N$ \\
\hline & & $\begin{array}{l}466 \\
467 \\
468\end{array}$ & $\begin{array}{l}\text { SSE } \\
\text { SSE, } 4760,4860,7068 \\
\quad 4860\end{array}$ & $N-S$ \\
\hline $\begin{array}{l}\text { EGEND } \\
\text { SSE }= \\
4860= \\
4840= \\
4760= \\
7063= \\
7068= \\
7067=\end{array}$ & $\begin{array}{l}\text { Rosman range rate tracking of GEOS-3 th } \\
\text { Wallops Island FPQ-6 C-Band Radar } \\
\text { Wallops Island FPS-16C-Band Radar } \\
\text { Bermuda FPQ-6 C-Band Radar } \\
\text { Goddard Laser } \\
\text { Grand Turk Laser } \\
\text { Bnrmuclis Laser }\end{array}$ & ATS-6. & & \\
\hline
\end{tabular}


TABLE 2. SUMMARY OF SSE RANGE RATE AND GROUND TRACKING DATA

(SHORT ARCS WITH TWO CONSECUTIVE SSE PASSES)

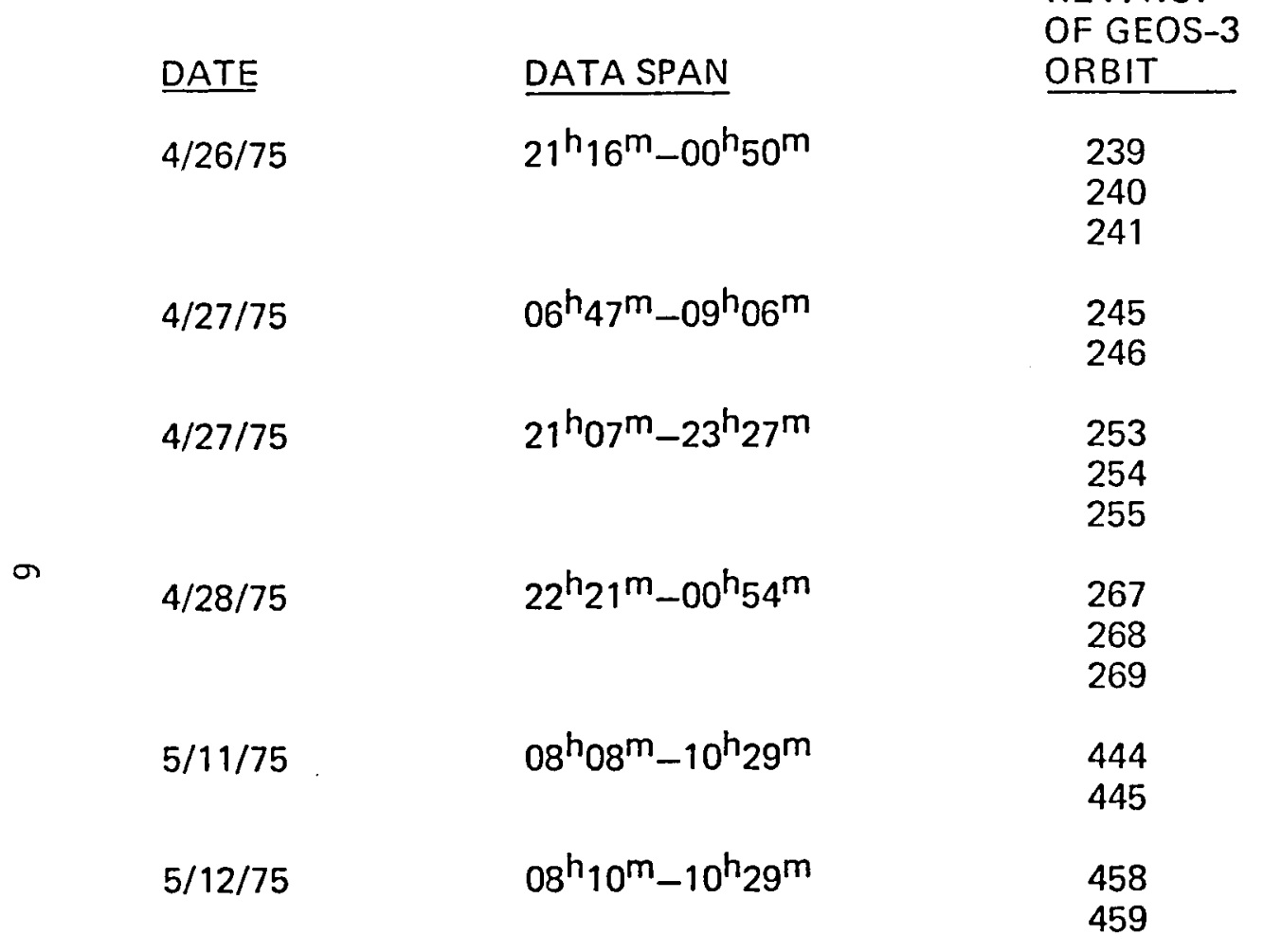

\section{STATIONS TRACKING*}

SSE

SSE, 4760, 4860, 7063 4860

SSE, $4760,4840,7063$

SSE, $4760,4840,7068,7063$

SSE, 4760

SSE, 4760, 4840, 7068

4840

4760

SSE, 4760, 4860, 7068

SSE, 4760,4860

SSE, 4760,4840

SSE, 4840, 7063

SSE, 4760,4860

SSE, 4760, 4860, 7063

\section{DIRECTION}

$\mathrm{N}-\mathrm{S}$

S-N

$N-S$

$\mathrm{N}-\mathrm{S}$

S-N

$S-N$

*See Table 1 legend. 
TABLE 3. SUMMARY OF TWO PASS ARCS OF LASER DATA

\begin{tabular}{|c|c|c|c|c|}
\hline DATE & DATA SPAN & $\begin{array}{l}\text { REV. NO. } \\
\text { OF GEOS-3 } \\
\text { ORBIT } \\
\end{array}$ & STATIONS TRACKING* & DIRECTION \\
\hline $7 / 26 / 75$ & $18^{h_{2}} 28^{m}-20^{h_{1}} 15^{m}$ & $\begin{array}{l}1525 \\
1526\end{array}$ & $\begin{array}{l}7063,7067,7068 \\
7063,7068\end{array}$ & $\mathrm{~S}-\mathrm{N}$ \\
\hline $8 / 8 / 75$ & $10^{h} 37^{m}-12^{h} 22^{m}$ & $\begin{array}{l}1704 \\
1705\end{array}$ & $\begin{array}{l}7063,7067,7068 \\
7063\end{array}$ & N-S \\
\hline $8 / 27 / 75$ & $12^{h_{41}} m_{-14^{h}}{ }^{5^{m}}$ & $\begin{array}{l}1974 \\
1975\end{array}$ & $\begin{array}{l}7063,7067,7068 \\
7063\end{array}$ & $\mathrm{~N}-\mathrm{S}$ \\
\hline $9 / 4 / 75$ & $22^{h} 06^{m}-23^{h_{53}}$ & $\begin{array}{l}2093 \\
2094\end{array}$ & $\begin{array}{l}7067 \\
7063,7067,7068\end{array}$ & $\mathrm{~S}-\mathrm{N}$ \\
\hline $11 / 26 / 75$ & $08^{h} 04^{m}-09^{h_{53}}$ & $\begin{array}{l}3259 \\
3260\end{array}$ & $\begin{array}{l}7063,7067 \\
7063,7067,7068\end{array}$ & $\mathrm{~S}-\mathrm{N}$ \\
\hline $2 / 23 / 76$ & $08^{h_{2}} 2^{m}-10^{h} 09^{m}$ & $\begin{array}{l}4518 \\
4519\end{array}$ & $\begin{array}{l}7067,7068 \\
7063,7067,7068\end{array}$ & $\mathrm{~N}-\mathrm{S}$ \\
\hline
\end{tabular}

* See Table 1 legend. 
The fourth data set consisted of 4 single passes of GEOS-3 with the ground tracks shown in Figure 2. These passes were each tracked by the three NASA laser stations. Whenever these arcs were used, they were always heavily weighted and were used solely to enforce a good set of baselines between the 3 stations.

In general, data weights used were based on the following sigmas:

$\begin{array}{ll}\text { Data Type } & \text { Sigma } \\ \text { SSE Range Rate } & 1 \mathrm{~mm} / \mathrm{sec} \\ \text { C-Band Range } & 1 \mathrm{~m} \\ \text { Laser Range } & .1 \mathrm{~m} \text { (data set } 3 \text { not used) } \\ \text { Laser Range } & 1 \mathrm{~m} \text { (data set } 3 \text { used) }\end{array}$

In spite of the apparent low weight given to the C-band data, it is essential to the solution because of the fact that the radars tracked continuousiy on almost all passes for which the spacecraft was above $10^{\circ}$ maximum elevation angle. Because of some bias uncertainty, a bias was adjusted for each radar for each arc.

\subsection{TRACKING POINT CORRECTIONS}

Precision reduced laser data is corrected during preprocessing so that the measurement is effectively made to the spacecraft center-of-mass. C-band data is flagged according to the transponder used (coherent or non-coherent), and is corrected in the GEODYN data reduction (T. Martin, et.al., 1972) to a spacecraft center-of-mass measurement. The coherent C-band transponder was used for all the passes listed in Tables 1 and 2 .

The SSE measurements to GEOS-3 are made to one of four antennas located in four quadrants around the spacecraft, each about a half meter from the center-of-mass. The data formats do not allow for the identification of the particular antenna in use, although the schedule normally calls for switching to the antenna closest to ATS-6. Based on the scheduling procedure, and the fact that all antennas are at the same vertical distance from the spacecraft 


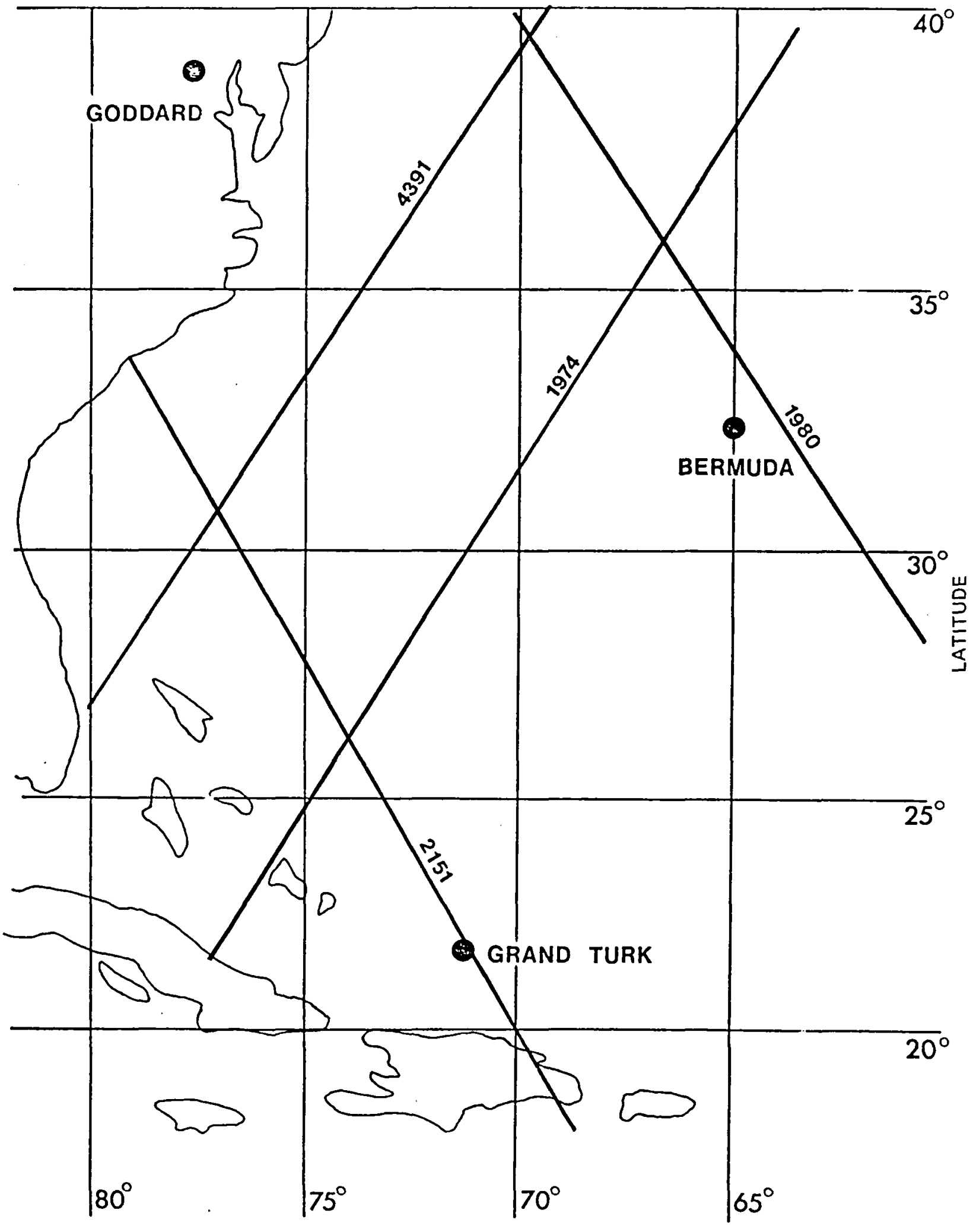

WEST LONGITUDE 
center-of-mass, the tracking point correction was made as if the transponder were located on a ring of $41.42 \mathrm{~cm}$ radius about the GEOS-3 vertical axis, $52.35 \mathrm{~cm}$ below the spacecraft center-of-mass.

The effect of the correction on SSE range rate measurements is on the order of $1 \mathrm{~mm} / \mathrm{sec}$, as is shown in Figure 3 which gives the effect of making the correction on measurements on GEOS-3 Rev 240. The effects on the GEOS-3 orbit are shown in Figure 4, with the orbit estimations having also included a GM adjustment (Data Set $1+$ Data Set 4). The main effect of making the correction is to move the orbit up by about the amount of the $z$ offset, requiring a corresponding adjustment in GM.

Table 4 shows the effects of the tracking point correction on estimated GM for various arcs which will be discussed below. The effects on the half day arc solutions are on the order of $+0.07 \mathrm{~km}^{3} / \mathrm{sec}^{2}$, while 1-2 Rev arc solutions are affected by a lesser amount and in the opposite direction. All GM solutions quoted below have had the tracking point correction applied.

\subsection{ESTIMATED VALUES OF GM}

The data sets discussed above have been reduced in various combinations and with 4 different gravity mode1s. The gravity models used were:

GEMI 7 (Goddard Earth Model 7) - contains no GEOS-3 data.

PGS558 - A very preliminary version of GEM 9 - contains some arcs of GEOS-3 ground tracking data.

GEM 9 [Lerch, et.al., 1977] (Goddard Earth Mode1 9) - contains LAGEOS data and extensive GEOS-3 data.

GEM 10 [Lerch, et.a1., 1977] (Goddard Earth Mode] 10) - same data as GEM 9 plus surface gravity data.

The data set combinations used were: 


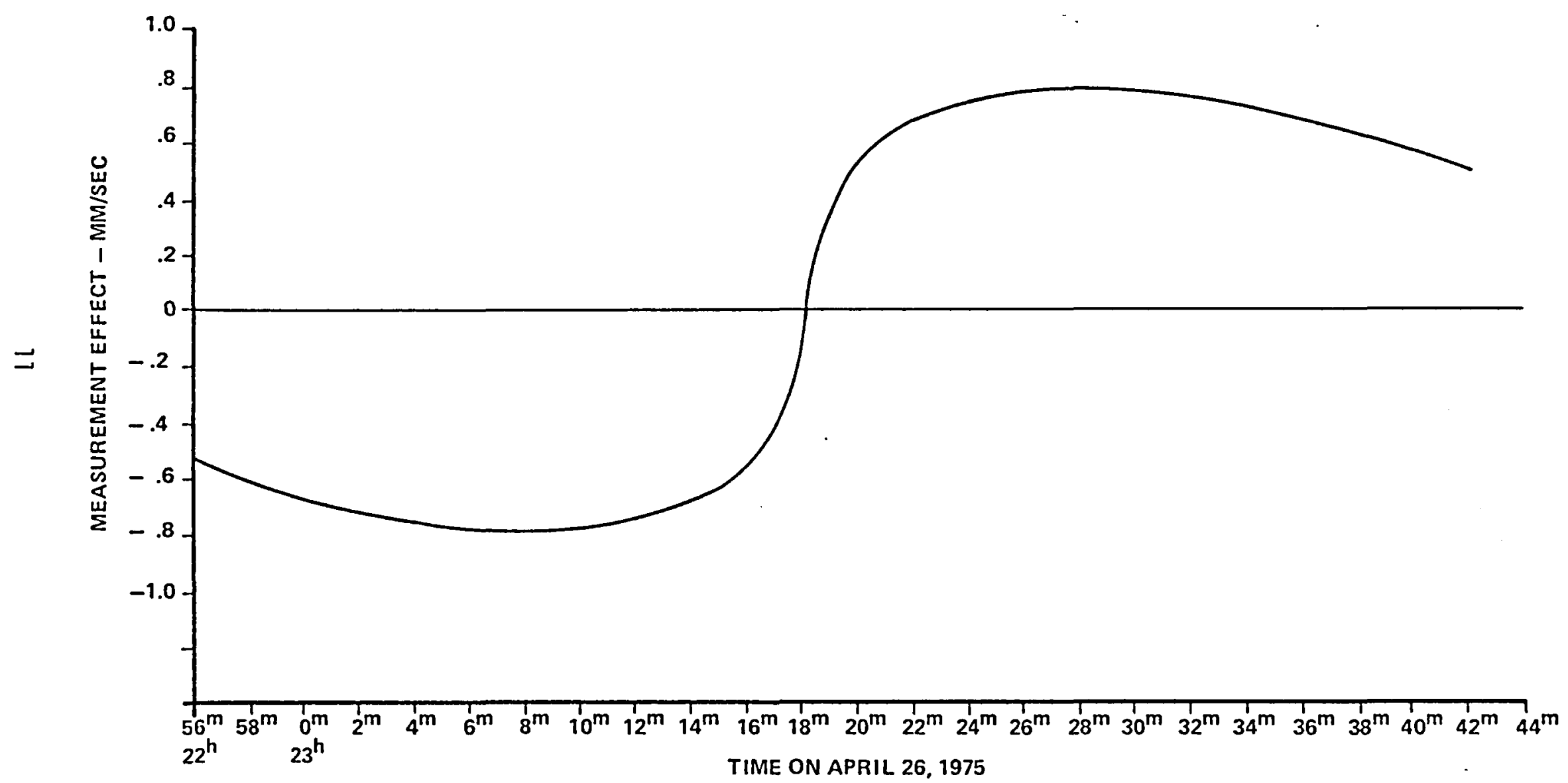

FIGURE 3. EFFECT OF TRACKING POINT CORRECTION ON SSE MEASUREMENTS ON GEOS-3 REV 240 

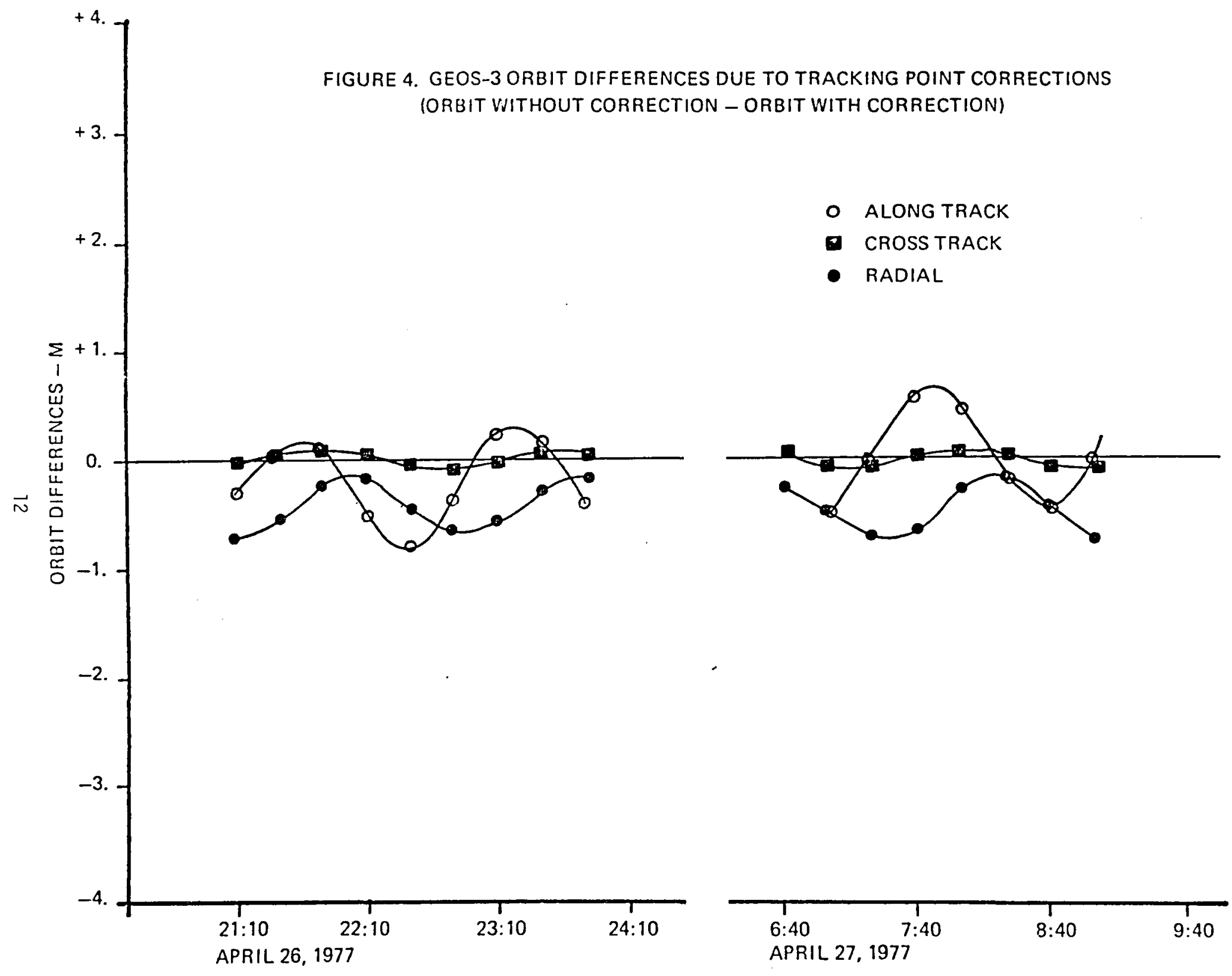
TABLE 4. EFFECT ON GM DUE TO SSE TRACKING POINT CORRECTION

$\underline{A R C}$

4/26 Half Day Arc

4/27 Half Day Arc

5/10 Half Day Arc

5/12 Half Day Arc

4/26, 5/12 Half Day Arcs

4/27, 5/10 Half Day Arcs

4 HALF DAY ARCS

SHORT SSE ARCS

$(\sigma \mathrm{L}=.1 \mathrm{~m})$
GM INCREMENT

$+.081 \mathrm{~km}^{3} / \mathrm{sec}^{2}$

$+.059$

$+.077$

$+.068$

$+.072$

$+.064$

$+.070$

$-.015$ 
1. Separate half day arcs from Data Set 1, plus Data Set 4.

2. Pairs of half day arcs from Data Set 1, plus Data Set 4.

3. Data Set 1 plus Data Set 4.

4. Data Set 2 plus Data Set 3.

5. Data Set 2 plus Data Set 4.

Table 5 shows the recovered values of GM for these various data set combinations and the 4 different gravity models. For a given gravity model, the major variations between solutions are due to different sensitivities to systematic errors, since only the short arc solutions are significantly affected by measurement noise. Such variations between solutions do not exceed $0.2 \mathrm{~km}^{3} / \mathrm{sec}^{2}$, even including the weakest solutions. Excluding the two weaker half day arc solutions (llay 10 and May 12) and the relatively weak SSE short arc and two pass laser arc solution, the solution to solution variations range from $.127 \mathrm{~km}^{3} / \mathrm{sec}^{2}$ for GEM 7 down to $.049 \mathrm{~km}^{3} / \mathrm{sec}^{2}$ for GEM 10 . In fact, the GEM 10 solution using a 114 half day arcs shows perfect agreement with the short arc GEM 10 solution. On the basis of consistent results using different data sets, the GEM 10 solutions would thus be expected to provide the most accurate $G M$ value.

A further basis for the choice of the GEM 10 results is provided by data fit to the GM and orbital solutions. Figure 5 shows the SSE range rate residual fit from the 4 half day arc solution, plotted against the recovered value of Gll. GEM 10 gives an rss of $1.11 \mathrm{~mm} / \mathrm{sec}$, compared to an rss of $1.16 \mathrm{~mm} / \mathrm{sec}$ for GEM 9. While this reduction is less than $5 \%$, it is a definite reduction, particularly when it is considered that the actual noise levels are around $1 \mathrm{~mm} / \mathrm{sec}$. The fits for PGS558 and GEM 7 are worse. Consequently, the adopted solution is the 4 half day SSE arc solution, with a Gll value of $398600.36 \mathrm{~km}^{3} / \mathrm{sec}^{2}$.

The accuracy of the solution depends upon the geopotential model error, and the degree to which the combination of arcs has led to a cancellation of geopotential and other error effects. The dominant error source is considered to be geopotential model error, followed by solar radiation pressure modeling 
TABLE 5. RECOVERED VALUES OF GM (IN KM ${ }^{3} / \mathrm{SEC}^{2}$ ) FROM ATS-6 TO GEOS-3 SSE RANGE RATE DATA AND GROUND TRACKING OF GEOS-3.

LISTED VALUES ARE GM - 398600. $\mathrm{KM}^{3} / \mathrm{SEC}^{2}$

\begin{tabular}{|c|c|c|c|c|c|c|}
\hline $\begin{array}{l}\text { GRAVITY } \\
\text { MODEL } \\
\text { USED }\end{array}$ & $\begin{array}{l}4 / 26 / 75 \\
\text { HALF DAY } \\
\text { ARC } \\
{ }_{\mathrm{O}}=.1 \mathrm{~m} \\
\end{array}$ & $\begin{array}{l}4 / 27 / 75 \\
\text { HALF DAY } \\
\text { ARC } \\
\sigma_{L}=.1 \mathrm{~m} \\
\end{array}$ & $\begin{array}{l}5 / 10 / 75 \\
\text { HALF DAY } \\
\text { ARC } \\
\sigma_{L}=.1 \mathrm{~m} \\
\end{array}$ & $\begin{array}{l}5 / 12 / 75 \\
\text { HALF DAY } \\
\text { ARC } \\
\sigma_{L}=.1 \mathrm{~m} \\
\end{array}$ & $\begin{array}{l}\text { MULTIARC } \\
\text { OF 4/26 AND } \\
5 / 12 \text { HALF } \\
\text { DAY ARCS } \\
o_{L}=.1 \mathrm{~m} \\
\end{array}$ & $\begin{array}{l}\text { MULTIARC } \\
\text { OF 4/27 AND } \\
5 / 10 \text { HALF } \\
\text { DAY ARCS } \\
\sigma_{L}=.1 \mathrm{~m} \\
\end{array}$ \\
\hline GEM7 & $.516 \pm .008$ & $.572( \pm .008)$ & $.652( \pm .014)$ & $.462( \pm .015)$ & $.508( \pm .007)$ & $.617( \pm .007)$ \\
\hline PGS558 & .537 & .468 & .475 & .319 & .504 & .496 \\
\hline GEM9 & .415 & .358 & .441 & .336 & .415 & .394 \\
\hline GEM 10 & .368 & .321 & .317 & .252 & .370 & .352 \\
\hline
\end{tabular}

MULTIARC OF 6 SHORT SSE ARCS PLUS

\begin{tabular}{l} 
GRAVITY \\
MODEL \\
USED \\
\hline
\end{tabular}

GEM7

GEM7

PGS558

GEM 9

GEM 10

\section{MULTIARC OF}

4/26, 4/27, 5/10 AND 5/12 HALF DAY ARCS

$\sigma_{\mathrm{L}}=.1 \mathrm{~m}$

$.567( \pm .005)$

.501

.400

.355
4 SINGLE PASS

LASER ARCS

$\sigma_{\mathrm{L}}=.1 \mathrm{~m}$

LASER ARCS

$\sigma_{L}=1.0 \mathrm{~m}$

$.505( \pm .035)$

$.490( \pm .024)$

.355

.399

.332

.355

NOTE: NUMBERS IN PARENTHESES ARE UNCERTAINTIES DUE TO NOISE ONLY. DATA SET FOR ALL HALF DAY ARC SOLUTIONS ALSO INCLUDES 4 SINGLE PASS LASER ARCS. 


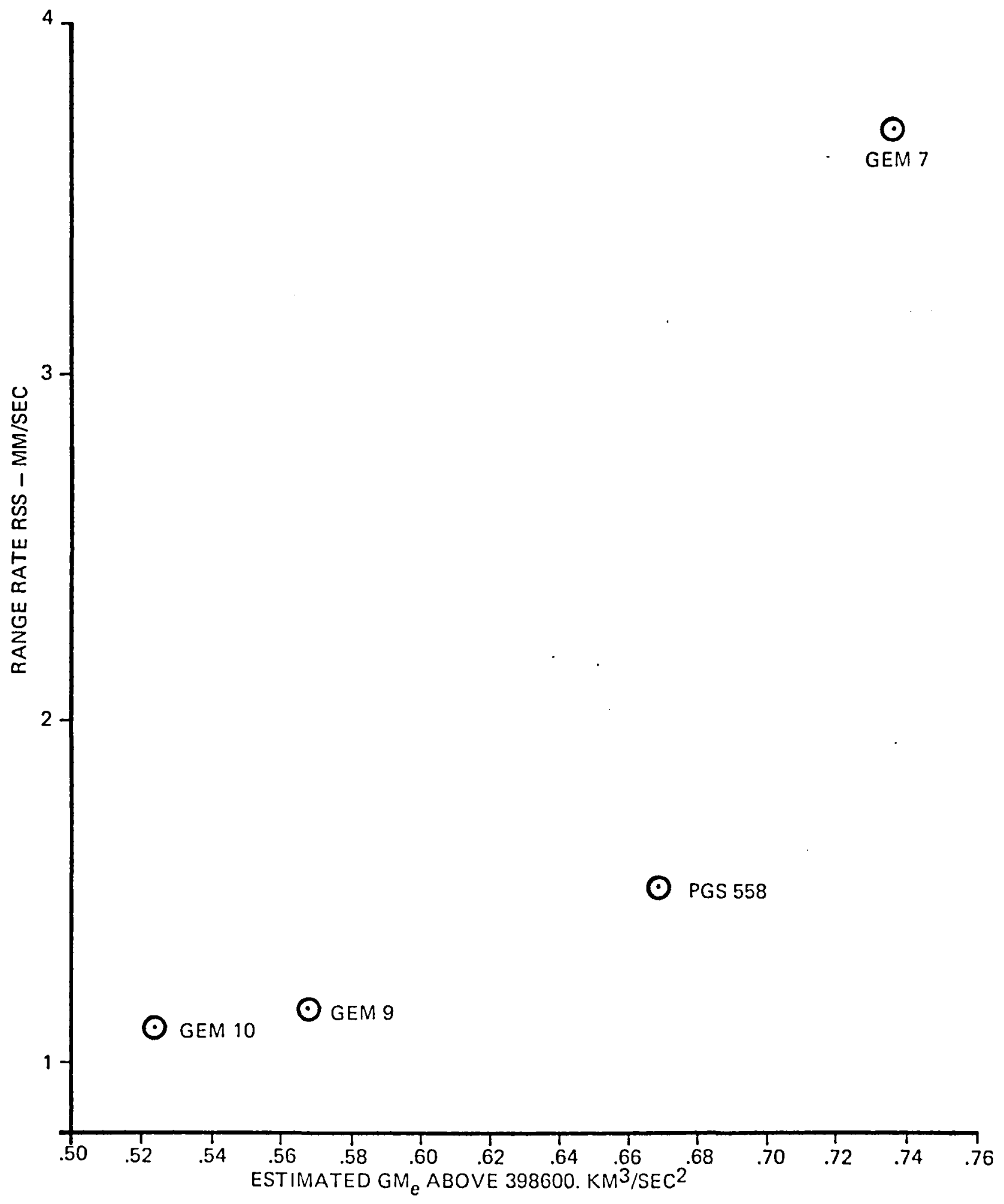

FIGURE 5. SSE RANGE RATE RSS FOR DIFFERENT GRAVITY MODELS

IN 4 HALF DAY ARCS 
for ATS-6 and propagation errors (tropospheric and ionospheric) for the C-band radar data. Although the geopotential errors are definitely correlated between all the models due to a common data set, the GEM 10 solution includes both GEOS-3 and surface gravity data that is not in GEM 7. From Table 5 , the differences between the GEII 7 and GEM 10 results are $0.212 \mathrm{~km}^{3} / \mathrm{sec}^{2}$ for the 4 half day arc solutions and $0.135 \mathrm{~km}^{3} / \mathrm{sec}^{2}$ for the short arc solutions, for an average difference of $0.17 \mathrm{~km}^{3} / \mathrm{sec}^{2}$. On the basis of the rss fits shown in Figure 5, and assuming that goodness of fit has a one-to-one relation with accuracy, we deduce that the GEM 7 error is more than 3 times the GEM 10 error. Even assuming that the GEM 7 and GEM 10 errors have a correlation of 1.0 , the expected value of the GEM 10 error is still $\frac{1}{\sqrt{2}}$ times the GEM 10 - GEM 7 difference, or $0.12 \mathrm{~km}^{3} / \mathrm{sec}^{2}$. Since the other errors are considered to have much smaller effects than this, we take $0.12 \mathrm{~km}^{3} / \mathrm{sec}^{2}$ to be the lo error level.

\subsection{STATION POSITIONS}

For the solutions quoted, all station coordinates were adjusted except for Rosman and the longitude of the Goddard laser (STALAS). Two station constraints were imposed: the two Wallops radars were constrained to move together and the Bermuda radar and laser were constrained to move together.

The recovered coordinates for the adopted set of half day arcs using GEM 10 are listed in Table 6 . The baselines between the laser stations have been constrained by the 4 single pass laser arcs. These arcs were chosen on the basis of data coverage and geometry, and the use of more than 4 passes (some 19 or more are available for GEOS-3) would provide primarily redundancy. Estimated baselines between the laser stations are listed in Table 7. Based on comparisons with single pass solutions using a larger number of arcs (Dunn, et.al., to be published in JGR, 1978; C. Martin and Butler, 1977), the GEM 10 baselines are thought to be accurate to the $10-15 \mathrm{~cm}$ level.

The heights recovered are on the order of 20-40 cm lower than those in the GEII 10 [Lerch, et.al., 1977] solution. A somewhat larger difference might have been expected on the basis of the difference in GM $\left(.12 \mathrm{~km}^{3} / \mathrm{sec}^{2}\right)$. Based in part on comparisons with the other solutions whose GM values are listed in Table 5, a 10 estimate of height error would be on the order of $50 \mathrm{~cm}$. 
TABLE 6. ESTIMATED STATION POSITIONS USING GEM 10 AND 4 HALF DAY ARCS OF SSE DATA

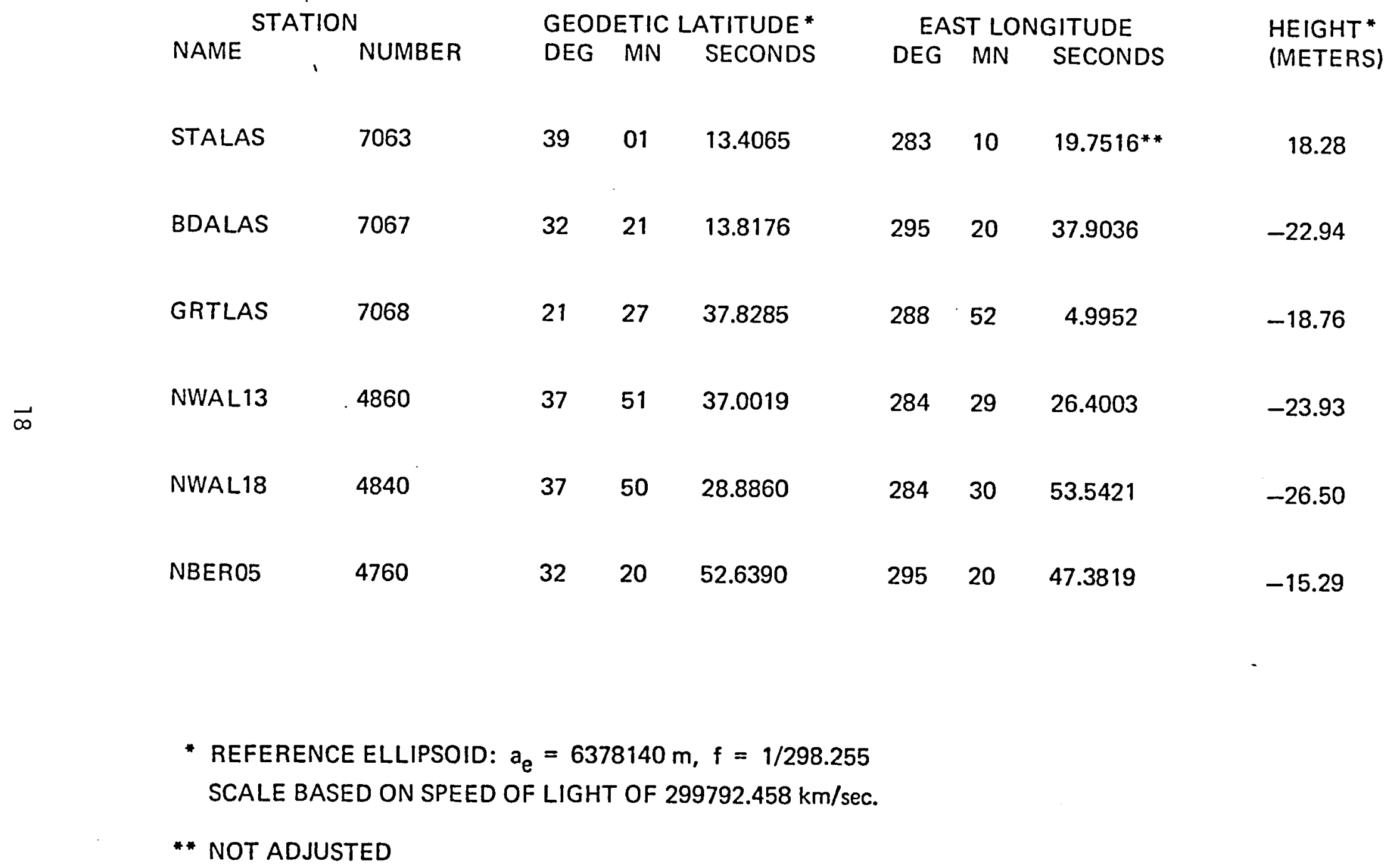


TABLE 7. ESTIMATED BASELINES AND STATION HEIGHTS

USING DIFFERENT GRAVITY MODELS

MULTIARC OF

4/26, 4/27, 5/10 AND 5/12

HALF DAY ARCS

GRAVITY

MODEL

USED

GEM7

$\vec{\sigma}$

PGS558

GEM9

GEM 10

STA-BDA
1322700.m

$+$

$41.92 \mathrm{~m}$

BASELINES*

STA-GRT

2012700.m

$+$

$24.25 \mathrm{~m}$

24.73

24.57

41.82

41.83

24.53
BDA-GRT

1364200 . $m$

$+$

$64.53 \mathrm{~m}$

17.85

65.08

.

65.08

65.04

(m)

20.33

18.67

18.28
HEIGHTS

GRTLAS

(m)

BDALAS

$-15.89$

$-22.44$

$-16.54 \quad-21.05$

$-18.41$

$-22.66$

$-18.76$

$-22.94$

*SCALE BASED ON SPEED OF LIGHT OF $299792.458 \mathrm{~m} / \mathrm{sec}$. 


\subsection{CONCLUSIONS}

Using tracking data involving two earth orbiting satellites is one of five methods which have been used for estimating GM during the past three years. All five methods give results within a $0.3 \mathrm{~km}^{3} / \mathrm{sec}^{2}$ band. The variety in the methods employed should be protection against the possibility that there is a common (overlooked) systematic error source affecting all the solutions. In fact, it may be possible to combine solutions and produce a more accurate GM value than any of the individual values. 


\section{REFERENCES}

Akin, E. L., et.al., "Refinements of the Masses of the Earth and the Moon from Observations of the Motion of the Automatic Interplanetary Stations Venera 4, Venera 5, Venera 6 and Venera 7 as They Departed from Earth," Soviet Physics - Doklady 16, June 1972. (Translated from Doklady Akademi i Nauk SSSR 20, 1303-1306, December 1971.)

Anderson, J. D. and D. E. Hilt, "Improvement of Astronomical Constants and Ephemerides from Pioneer Radio Tracking Data," AIAA Journal 7, 1048-1054, June 1969.

Esposito, P. B. and S. K. Wong, "Geocentric Gravitational Constant Determined from Mariner 9 Radio Tracking Data," presented at the International Symposium on Earth Gravity Models and Related Problems, St. Louis, MO, August 1972 .

Esposito, P. B. and A. Y. T. Ng, "Geocentric Gravitational Constant Determined from Spacecraft Radiometric Data," Physics of the Earth and Planetary Interiors 12, 283-289, 1976.

Esposito, P. B., "Evaluation of Geocentric Gravitational Constant," Abstract in EOS 59, p. 260, Apri1 1978.

Gaposchkin, E. M. and K. Lambeck, "1969 Smithsonian Standard Earth," Smithson. Astrophys. Observ. Spec. Rep. 315, May 18, 1970.

King, R. H., C. C. Counselman III, and I. I. Shapiro, "Lunar Dynamics and Selenodesy: Results from Analysis of VLBI and Laser Data," JGR 8l, $6251-6256,1976$.

Lerch, F. J., et.a1., "Gravity Model Improvement Using GEOS-3 (GEM 9 and 10)," GSFC Document X-921-77-246, September 1977.

Lundquist, C. A. and G. Veis, "Geodetic Parameters for a 1966 Smithsonian Institution Standard Earth," Smithson. Astrophys. Observ. Spec. Rep. 200, Vot. 2, 1966.

Martin, C. F. and M. L. Butler, "Calibration Results for the GEOS-3 Altimeter," NASA CR-141430, September 1977.

Martin, T. V., C. C. Goad, M. M. Chin, and N. E. Mullins, GEODYN, Vol. I, II, III, and IV, Wolf Research and Development Corp., Riverdale, MD, 1972.

Mottinger, N. A. and W. L. Sjogren, "Consistency of Lunar Orbiter II Ranging and Doppler Data," JPL Space Programs Summary 37-46, Vo1. 3, July 1967.

Pease, G., et.al., "The Mariner V Flight Path and Its Determination from Tracking Data," JPL TR 32-1363, July 1969, p. 7. 
Sjogren, W. L., et.al., "Physical Constants as Determined from Radio Tracking of the Ranger Lunar Probes," JPL TR 32-1057, December 1966.

Williams, J. G., "Project Scientific Achievements from Lunar Laser Ranging," 37-50, Scientific Applications of Lunar Laser Ranging, D. Mulholland, ed. , D. Reidel 1977.

Wong, S. K., "Deep Space Station Locations and Physical Constants Solutions of Surveyor Missions," JPL Space Programs Summary 37-52, Vo1. 2, July 1968. 


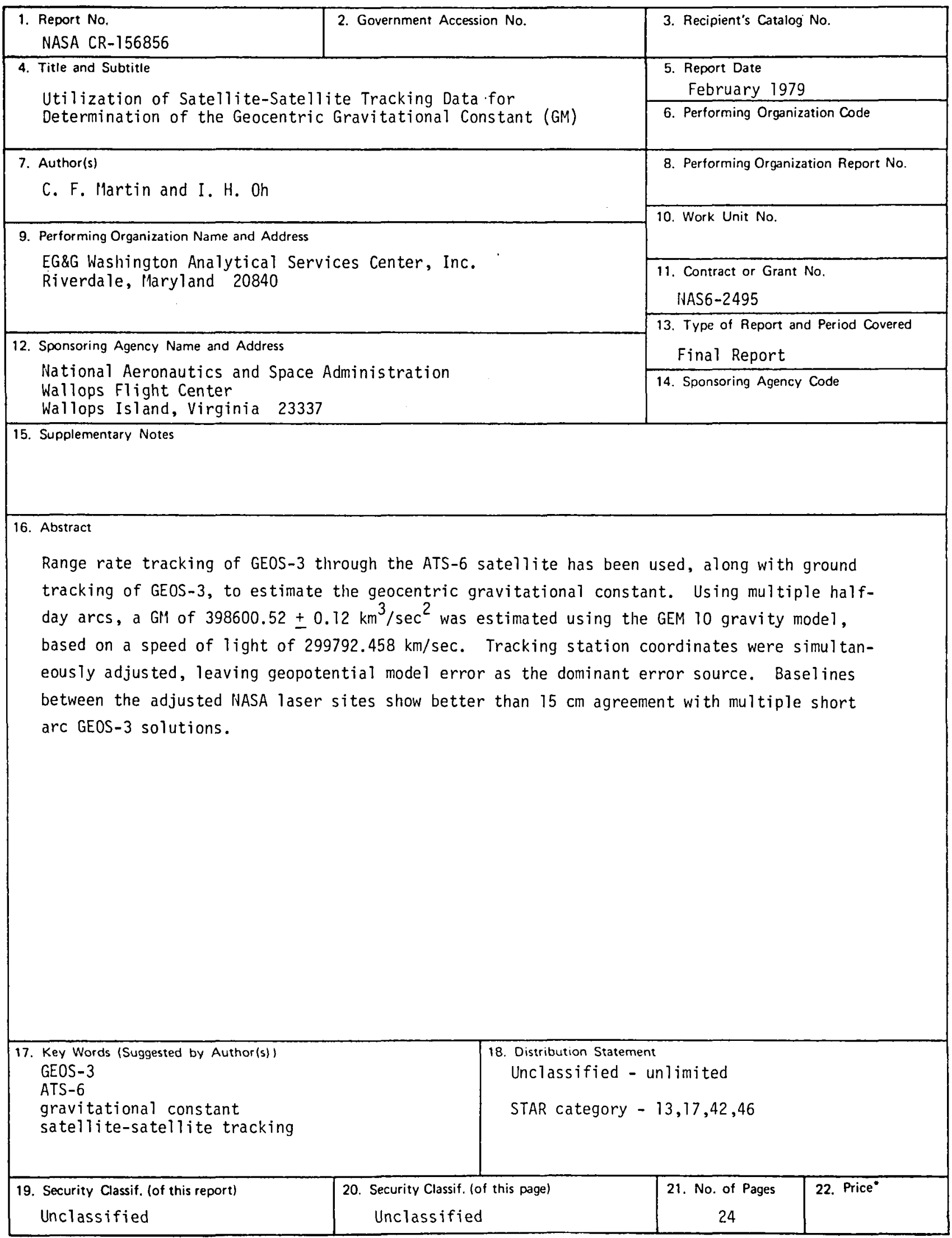

"For sale by the National Technical Information Service. Springfield, Virginia 22151 


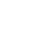

, 
National Aeronautics and

Space Administration

SPECIAL FOURTH CLASS MAIL BOOK

Wallops Island, VA

23337

Official Business

Penalty for Private Use. 5300
Postage and Fees Paid

National Aeronautics and

Space Administration

NASA-451 